\title{
Line Probe Assay
}

National Cancer Institute

\section{Source}

National Cancer Institute. Line Probe Assay. NCI Thesaurus. Code C102656.

A technique in which polymerase chain reaction is used to amplify specific nucleic acid sequences in a biospecimen. The product of this reaction is then applied to a nitrocellulose test strip containing complementary DNA probes. 